\title{
PENATALAKSANAAN AMELOBLASTIK KARSINOMA PADA MANDIBULA DENGAN RESEKSI SEGMENTAL DAN PEMASANGAN MANDIBLE RECONSTRUCTIVE PLATE
}

\author{
*Bambang Widjanarko *z Masykur Rahmat \\ •Program Studi Ilmu Bedah Mulut, Program Pendidikan Dokter Gigi Spesialis, FKG UGM \\ "Bagian Bedah Mulut FKG UGM
}

\begin{abstract}
ABSTRAK
Ameloblastik Karsinoma merupakan tumor odontogenik yang jarang ditemukan, dan bersifat agresif. Pada awalnya tumor ini menunjukkan gambaran histologis seperti ameloblastoma, tapi kemudian kehilangan diferensiasi dan menjadi malignan, walaupun klinisnya adalah ameloblastoma biasa, dan bermetastase ke kelenjar limfe atau melalui kelenjar limfe. Perawatannya sama dengan lesi karsinoma intraoseus lainnya, tapi bila telah mengalami metastase maka prognosanya buruk.

Tujuan penulisan ini adalah untuk melaporkan keberhasilan operasi reseksi segmental dan pemasangan mandible reconstructive plate (MRP) pada seorang pasien ameloblastik karsinoma.

Laporan kasus pasien perempuan berusia 47 tahun datang ke poliklinik Bedah Mulut RSUP Dr. Sardjito Yogyakarta dengan keluhan utama benjolan pada rahang bawah depan sebelah bukal regio $3.3-4.7$, tidak terasa sakit, konsistensi keras, wama sesuai dengan jaringan sekitar, ukuran $7 \times 4 \times 2 \mathrm{~cm}$, muncul kurang lebih 3 tahun yang lalu, mula-mula kecil kemudian membesar. Penatalaksanaan kasus ini adalah operasi reseksi segmental dan pemasangan MRP di bawah anestesi umum. Prognosis dubia ad bonam.

Kesimpulan pada kasus ini pemasangan MRP mampu menjaga kontinuitas mandibula kanan-kiri, dan sebagai tempat perlekatan otot-otot mylohiod agar lidah tidak jatuh ke laring, serta untuk mempertahankan estetik dan fungsinya. Mai Ked Gir, Juni 2010; 17(1): 29-34
\end{abstract}

Kata kunci: ameloblastik karsinoma, reseksi segmental, mandible reconstructive plate

ABSTRACT

Ameloblastic carcinoma is an aggressive odontogenic tumor and rarely found. Initially this tumor resembles an ameloblastoma histological, but loses differentiation and behaves malignantly, although its clinical appearance is ordinary ameloblastoma, and spread to lymph nodes. The treatment is that of an intraosseous carcinoma, but the prognosis is poor if metastases are present.

Purpose of this was to report success of segmental resection surgery and installation of mandible reconstructive plate (MRP) of an ameloblastic carcinoma patient.

Case report a woman having age 47 years had come to Oral and Maxillofacial Surgery clinic of Dr. Sardjito General Hos. pital, Yogyakarta. With main sigh of bump at the front side of lower jaw on buccal region of $3.3-4.7$, painless, firm consistency, color as normal, measure $7 \times 4 \times 2 \mathrm{~cm}$, emerged approximately 3 years ago, originally small then became bigger. bonam.

Treatment of this case is segmental resection and installation of MRP under general anesthesia. Prognosis dubia ad

Conclusion, the purpose of installation of MRP was to koep the mandible continuity, for placement of mylohioid muscle, and also for maintain the esthetic and function. Maj Ked Gri, Juni 2010; 17(1):29-34

Key words: ameloblastic carcinoma, segmental resection, mandible reconstructive plate.

\section{PENDAHULUAN}

Ameloblastoma adalah tumor jinak odontogen yang paling sering ditemukan, bersifat agresif lokal dan infiltratif, berasal dari sisa-sisa komponen epitel gigi yang tertinggal di dalam tulang alveolar. ${ }^{13}$ Ada 4 sumber epitel, yaitu: (1) epitel seres atau dental lamina, (2) epitel enamel atau ameloblast, (3) epitel Malasez, dan (4) lapisan sel basal yang melapisi epitel. ${ }^{1}$ Umumnya ameloblastoma muncul pada kelompok usia 30 - 50 th, asimptomatik, pertumbuhannya lambat, dan bersifat lokal, serta tidak terdapat metastase. ${ }^{1,2}$ Bila mengenai maksila, ameloblas- toma dapat menginvasi dasar tengkorak sehingga menyebabkan kematian. Sifatnya mudah rekuren apabila operasi eksisi tidak bersih.

Keganasan pada ameloblastoma telah lama menjadi topik diskusi dan kontroversi para ahli. Ada beberapa pendapat yang menyatakan bahwa ameloblastoma bersifat malignan apabila terdapat metastase, meskipun gambaran histologisnya jinak, pendapat yang lain menyatakan ameloblastoma bersifat malignan apabila klinisnya agresif meskipun tidak terdapat metastase. Lesi ini seringkali menunjukkan gambaran histologis yang berbeda atau atipikal. Ada beberapa jenis tumor odontogen yang malig- 
nan, yaitu: ameloblastoma malignan, ameloblastik karsinoma, odontogenik karsinoma, dan primari intraosseous karsinoma.'

Ameloblastoma Malignan gambaran histologisnya ameloblastoma biasa, tetapi mengalami metastase ke kelenjar lymfe atau tempat lain yang jauh letaknya terutama ke paru-paru. ${ }^{1,2}$ Ameloblastik karsinoma jarang ditemukan dan agresif. Perbedaan dengan ameloblastoma malignan, terletak pada epitelnya yang merupakan campuran dari sel-sel yang secara sitologis malignan, meskipun lesinya masih tetap nampak sebagai ameloblastoma. Insidensi ameloblastik karsinoma lebih besar dua kali lipat dibanding ameloblastoma malignan. Menjalar ke kelenjar limfe atau melalui kelenjar limfe dan selanjutnya gambaran mikroskopiknya berubah menjadi seperti squamous cell carcinoma. ${ }^{1,2}$ Odontogenik Karsinoma sifatnya agresif dan destruktif, terdiri dari sel-sel epitel dengan diferensiasi buruk. Gambaran radiografisnya berupa radiolusensi honeycomb yang difuse. ${ }^{1}$ Primari Intraosseous Karsinoma merupakan squamous cel carcinoma pada rahang yang tidak menunjukkan tanda-tanda berasal dari sel epitel permukaan, atau hasil metastase dari tempat lain.'

\section{LAPORAN KASUS}

Seorang perempuan usia 47 tahun, datang ke poli Bedah Mulut RSUP Dr. Sardjito Yogyakarta pada tanggal 19 Maret 2010 dengan keluhan benjolan di dagu yang menyebabkan wajah menjadi asimetris. Dari anamnesa, benjolan muncul sejak 3 tahun yang lalu, pada awalnya tidak ada rasa sakit, tetapi sejak beberapa bulan terakhir benjolan tersebut kadang terasa agak sakit, dan semakin membesar sehingga mengganggu fungsi pengunyahan, bicara dan estetik (Gb.1).

Pemeriksaan fisik penderita didapatkan kesadaran umum baik, gizi cukup, berat badan $47 \mathrm{~kg}$. tinggi badan $150 \mathrm{~cm}$, kesadaran compos mentis. Vital signs T: $140 / 80 \mathrm{mmHg}, \mathrm{N}: 84 \mathrm{x} /$ menit, R: $20 \mathrm{x} /$ menit, afebris, sklera tidak ikterik, konjungtiva tidak anemis, ekstremitas tidak ada kelainan. Pemeriksaan ekstra oralnya muka asimetris, benjolan di dagu ukuran $7 \times 4 \times 2 \mathrm{~cm}$, limponodi submental teraba, pipi dalam batas normal, bibir dalam batas normal, hidung dalam batas normal. Pemeriksaan intra oral terdapat benjolan sebelah bukal dan lingual pada alveolar regio gigi 3.3-4.7, ukuran $7 \times 4 \times 4 \mathrm{~cm}$. Palpasi keras, tidak nyeri tekan, warna menyerupai jaringan sekitar, tidak ada krepitas dan fluktuasi, oral hygiene sedang, gigi yang ada hanya 3.3 dan 3.4. (Gb.2).

Pemeriksaan laboratorium darah rutin serta foto ronsen thorax dalam batas normal. Hasil OPG, terlihat area radiolusen dengan batas tegas pada mandibula anterior yang memberi kesan sebagai gambaran suatu tumor (Gb.3). Gambaran CT-Scan terlihat bagian anterior tulang mandibula teresorbsi (Gb.4). Hasil pemeriksaan histologi biopsi: secara mikroskopik: sel ameloblastik karsinoma diantara jaringan ikat, jaringan dilapisi epitel gepeng yang menebal dengan hiperplasi epitelmatosa dengan nekrosis dan perdarahan. Kesan: ameloblastik karsinoma (Gb.5). Diagnosa: ameloblastik karsinoma, diagnosa banding: ameloblastoma dan ameloblastoma malignan.

\section{PENATALAKSANAAN KASUS}

Dari hasil pengamatan dan pemeriksaan penderita, direncanakan untuk dilakukan operasi reseksi segmental dengan frozen section biopsy dan pemasangan mandible reconstructive plate (MRP) dengan pertimbangan lesi cukup besar.

Jalannya operasi: setelah pasien teranestesi dibuat gambar disain insisi sekitar 1 jari di bawah margo inferior mandibula (Gb.6a), kemudian dilakukan insisi lapis demi lapis sampai ke tulang, semua jaringan dipisahkan (Gb.6b). Dilakukan insisi intra oral di bagian bukal dan lingual alveolar (Gb.6c), lalu jaringan tulang dibuka dari arah bukal sampai terlihat jaringan massa dengan jelas. Pemisahan massa tumor dengan menggunakan rasparatorium sampai ke bagian tulang yang terlihat bersih dari tumor. Lalu dilakukan reseksi pada bagian ramus kanan dan kiri mandibula di bagian yang bebas tumor (sekitar $1 \mathrm{~cm}$ dari tepi tumor) dengan gigly saw. Seluruh jaringan tulang yang berisi tumor diambil, ruang bekas reseksi diperiksa dan dipastikan jaringan tumor sudah bersih (Gb.6d). Potongan tulang dan massa tumor diambil untuk dilakukan frozen section biopsy. Setelah hasil biopsi keluar dilakukan pemasangan MRP dari bahan titanium tipe lurus 11 lubang dan sekrup titanium 4 buah untuk menjaga kontinuitas tulang (Gb.6e). Luka bekas insisi di kembalikan pada keadaan semula dan di jahit lapis demi lapis. Pemasangan drain kassa ekstra oral, dan kontrol perdarahan.

Perawatan paska operasi diberikan obat-obatan, R/ ceftriaxon injk 1 amp/8 jam, R/ remopain injk $1 \mathrm{amp} / 8 \mathrm{jam}, \mathrm{R} /$ dexamethasone injk $1 \mathrm{amp} / 8$ jam, R/ kalnex injk 1 amp/8 jam (sampai perdarahan berhenti) dan obat kumur betadine. Diinstruksikan diet cair melalui NGT selama lima hari, pada hari ke enam diganti diet cair per oral dan obat injeksi diganti obat oral. Pada hari ke empat drain diambil seluruhnya. Pasien dirawat inap selama tujuh hari dan dilanjutkan dengan rawat jalan.

\section{EVALUASI PASKA OPERASI}

Pada hari ke tujuh paska operasi dilakukan pengangkatan jahitan sebagian, dan hari ke sepuluh seluruh jahitan di kulit di ambil. Satu bulan paska operasi, luka operasi sudah dinyatakan baik serta tidak terlihat tanda-tanda infeksi. Wajah penderita tampak simetris kembali (Gb.7), hasil foto panoramik terlihat kontinuitas ramus mandibula kanan-kiri terjaga de- 


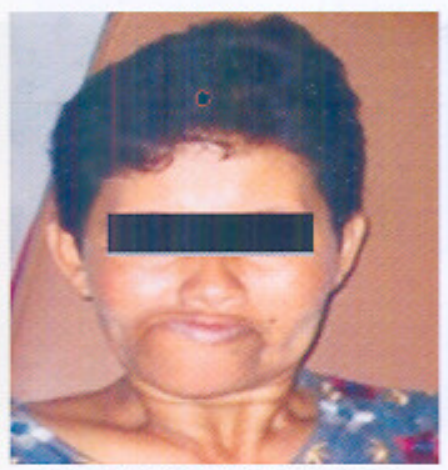

Gambar 1. Wajah depan

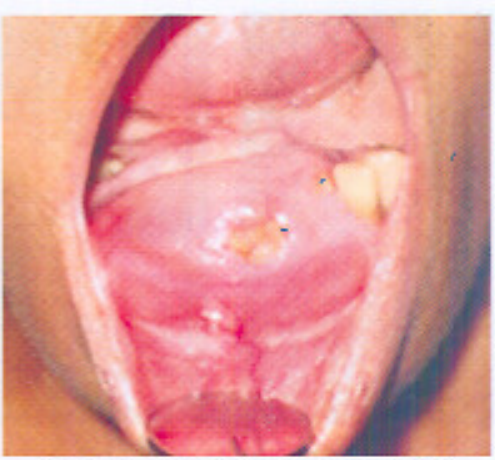

Gambar 2. Benjolan intra oral

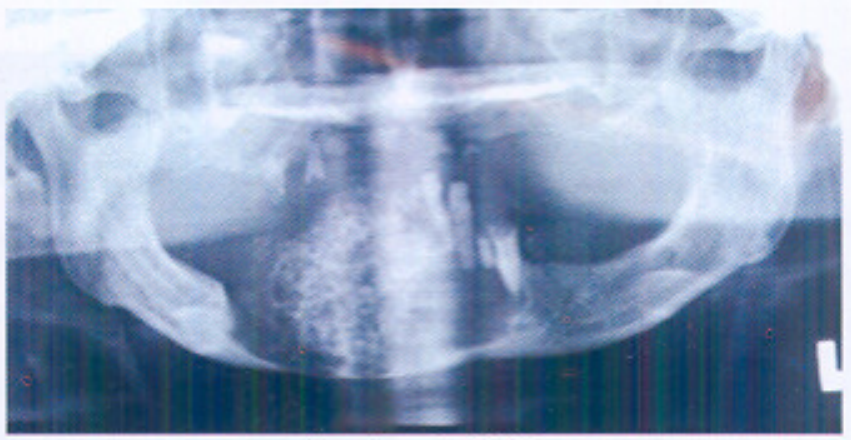

Gambar 3. OPG
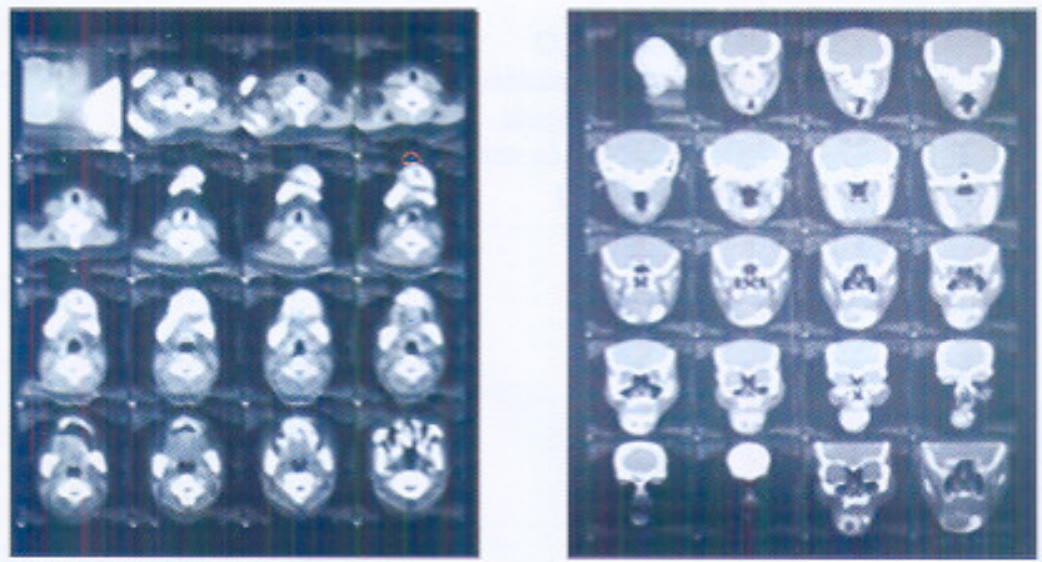

Gambar 4. CT Scan

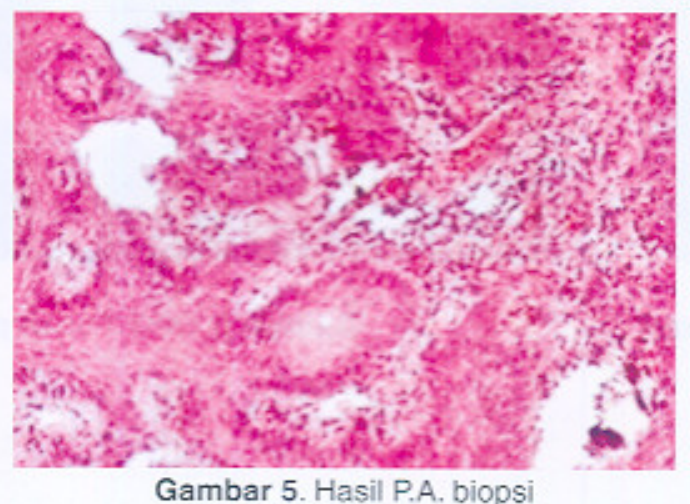

Gambar 5. Hasil P.A. biopsi 

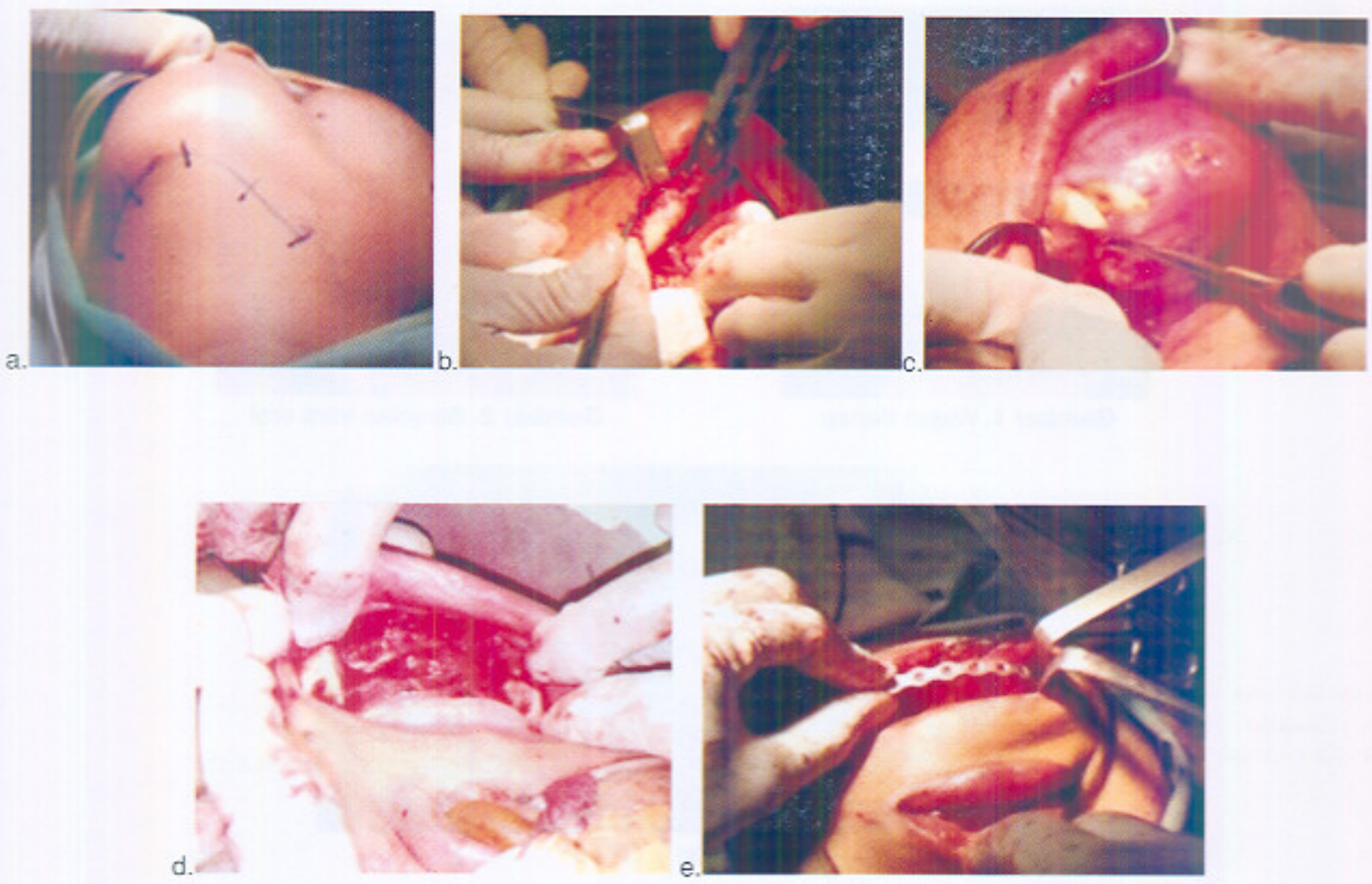

Gambar 6. a. Desain insisi E.O

b. Insisi sampai ketulang

c. Insisi bagian lingual

d. Tulang mandibula setelah di reseksi

e. MRP terpasang

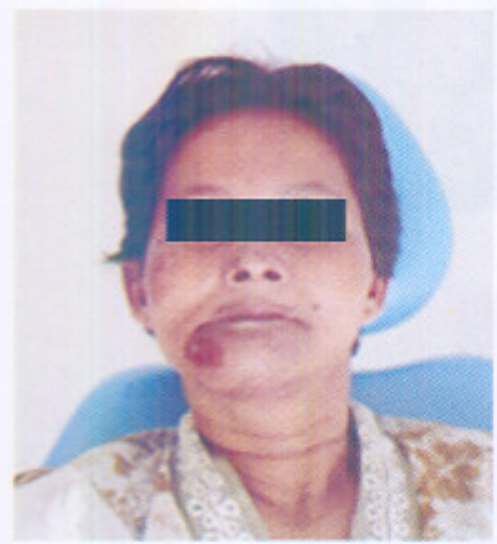

Gambar 7.1 bulan paska operasi

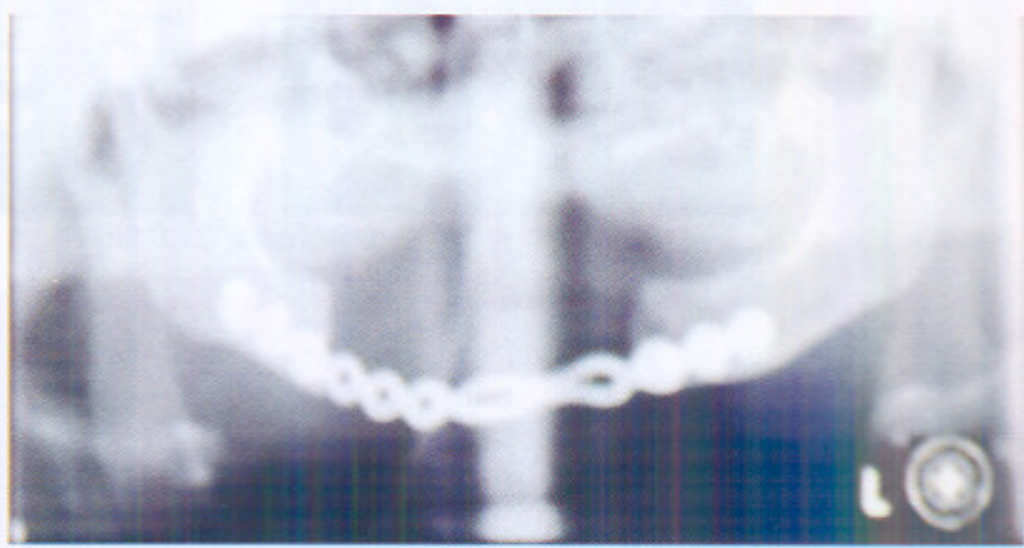

Gambar 8. OPG 1 bulan paska operasi 
ngan baik melalui MRP (Gb.8).

\section{PEMBAHASAN}

Perawatan ameloblastoma umumnya ditentukan berdasarkan struktur histopatologis tumor, luas jaringan yang terlibat dan keuntungan yang akan diperoleh., ${ }^{45}$ Pada tumor mandibula, baik yang jinak maupun ganas, apabila belum melibatkan seluruh dimensi tulang rahang, perawatan yang umum dilakukan adalah operasi reseksi segmental mandibula. Rekonstruksi paska reseksi dapat dilakukan dengan pemasangan kawat (Kirschner Wire), MRP, autotransplantasi dari tulang iga atau tulang pinggul. ${ }^{6}$

Tindakan pada kasus ini adalah mengangkat seluruh jaringan tumor, dengan reseksi tulang mandibula sampai ke daerah yang bebas tumor, hal ini dilakukan karena sifat dari ameloblastik karsinoma yang metastasis dan rekuren.

Setelah masa tumor diambil seluruhnya, rongga bekas tumor dikuret sampai bersih agar tidak terjadi kekambuhan di kemudian hari. Pemasangan MRP tipe lurus sepanjang 11 lubang di gunakan untuk menjaga kontinuitas tulang mandibula kanan-kiri sehingga estetik, fungsi pengunyahan dan bicara pasien tidak terganggu. Dipasang drain kassa sepanjang $20 \mathrm{~cm}$ untuk mengontrol perdarahan, menghindari dead space dan mengurangi pembengkakan paska operasi.

Hasil pemeriksaan patologi anatomi paska operasi adalah ameloblastoma, hal ini menguatkan diagnosa awal dimana tumor berasal dari ameloblastoma yang mengalami diferensiasi sel menjadi malignan. Prognosa pada pasien ini masih cukup baik, karena belum mengalami metastase yang meluas, serta dilakukan operasi reseksi segmental sampai ke bagian tulang rahang yang bebas tumor, sehingga kekambuhan dapat dihindari.

\section{KESIMPULAN}

Pada kasus ini, pengambilan masa tumor dengan cara reseksi dan pemasangan MRP berhasil dengan baik. Pengambilan masa tumor harus dilakukan dengan cermat berdasarkan pemeriksaan klinis, biopsi dan radiologis sebagai pemeriksaan penunjang sehingga diagnosis yang tepat dapat ditegakkan dan memperkecil risiko timbulnya kelainan patologis di kemudian hari. MRP dipasang untuk menjaga kontinuitas mandibula kanan-kiri, dan sebagai tempat perlekatan otot-otot mylohiod agar lidah tidak jatuh ke laring, serta untuk mempertahankan estetik dan fungsinya. Rekurensi ameloblastik karsinoma cukup tinggi sehingga pasien perlu dilakukan pemeriksaan ronsen panoramik secara berkala.

\section{DAFTAR PUSTAKA}

1. Philip Sapp J: Contemporary Oral and Maxillotacial Pathology, $2^{\text {no }}$ ed, St. Louis, Missouri: Mosby, 2004: 13643,159-61.

2. Cawson RA: Cawson's Essentials of Oral Pathology and Oral Medicine, $7^{\text {th }}$ ed, London; Churchill Livingstone, 2002: $121-4$

3. Archer HW: Oral and maxillofacial Surgery, vol $1,3^{\text {th }}$ ed, Philadelphia: WB Saunders Co., 1975: 518-84, 735-47. 847.

4. Kruger GO: Textbookof oral surgery, $4^{\text {th }}$ ed. St. Louis: The Mosby Co., 1974: 568-70.

5. Laskin DW: Oral and maxillofacial surgery, vol II, St. Louis: CV Mosby, 1985: 450-8, 627-36.

6. Huvos AG: Bone Tumors, treatment and prognosis., $2^{\text {ns }}$ ed., W.B. Saunders Company., Philadelphia. 1991.

\section{Majalah Kedokteran Gigi terbit bulan Juni \& Desember}

